\section{SERC failing astronomers?}

SIR-As a senior member of the research staff of the Royal Greenwich Observatory (RGO), I found your News article "Observatory move stirs passions" (Nature 321, 4 ; 1986) most interesting. At RGO I am somewhat of a "dove" about the move because I am concerned that a refusal to accept the decision of the Science and Engineering Research Council (SERC) in this matter, particularly on political grounds, could in the long term be bad for UK science. It may be better to accept a bad decision made by scientists now, in the hope of good decisions by scientists in the future, than to give ourselves over to overtly political decisions for ever

Why does the decision seem so bad and arouse so much passion? Primarily because the stated reasons make no sense and are widely perceived to be a cover for a cost-cutting exercise. Placing RGO in a more stimulating academic environment is a worthy goal, but it would command more credibility if the actions of SERC over the past few years (an overall rundown at RGO, a further cut of our research in favour of a support role and failure to support efforts to strengthen the existing link with the University of Sussex) were consistent with this objective.

The expectation that the move can be self-financing also seems questionable. How can it be self-financing compared, for example, to the unexplored option of selling the castle and grounds at Herstmonceux while retaining the observatory, which is mostly in a modern office block in one corner of the property?

Thus most people believe that the move is an administrative device to cut costs in optical astronomy to free funds for new activities. They are reinforced in this belief by the rundown of RGO over recent years and the failure of SERC to place any of its New-Blood positions in university departments specializing in optical astronomy (only fifteen went to astronomy as a whole).

Thus, as an optical astronomer who believes in the importance and intellectual validity of my subject, I was opposed to the decision for exactly the same reasons as it seems to be attractive to SERC.

I do not believe that there is any wickedness involved in the decision or the under-appreciation of optical astronomy; simply muddle. Two more examples of SERC's confusion appear in your article. First, the publication of the results of the poll of staff in RGO about the move: the survey was co-sponsored by the RGO staff side who had the privilege of seeing them for the first time in your pages. Second, the gymnastics by Harry Atkinson as portrayed in your final paragraph suggest that political considerations (at least of a regional nature) are indeed part of

\section{SERC's desiderata.}

I am sorry to say that all this makes my stated support of SERC's decision pretty thin. What is needed to get SERC off the hook is an independent review as sought by the East Sussex County Council and preferably along scientific lines. I propose as chairman of this review the vicechancellor of the University of Sussex, Sir Denys Wilkinson, who should be joined by a world-renowned foreign optical astronomer and a leading representative of our own (non-political) astronomical community. Such a group might have the moral authority to persuade everybody to accept its decision.

It is clear to me, however, that the organization most in need of serious investigation is the Swindon headquarters of SERC. It has shown itself much more eager to control the minutiae of activities in its laboratories, such as RGO, than to try to bring new resources into (in particular) a pure science like astronomy. From my perspective, they have singularly failed me, and other active scientists whether in universities or in their own laboratories, in this regard.

Rose Lodge,

Michael Penston

Magham Down,

Hailsham

E. Sussex, BN27 1PR, UK

SIR-As representatives of the staff of the Royal Greenwich Observatory (RGO), we read with interest your analysis (Nature 321, $4 ; 1986$ ) of the current debate on the future location of the Observatory. Even though it is our lives and careers that will be affected by the outcome of this debate, we feel we are but pawns in the Science and Engineering Council (SERC)'s game. For example, SERC has refused to allow the report of the Kingman panel to be circulated among RGO staff, although it is obvious that members of the press and others have had copies. We also learnt of the results of the survey of RGO staff for the first time in your columns, and although this has been traced to an administrative bungle rather than a deliberate act, it demonstrates SERC's scant regard for the people who will be most involved. Staff have been asked to state their preferences, but in view of all that has gone before they wonder how much notice will be given to their opinions.

We have now received the results of the staff survey but interpret the numbers very differently from your informant. In the first place, the questions did not even mention the possibility of remaining at Herstmonceux. Almost all staff are strenuously opposed to any move and have said so consistently and vociferously from the outset. Had you been present when the chairman of SERC, Professor E.W.J. Mitchell, met staff at Herstmonceux on 1 May, you too would have been in no doubt of their views. Second, the apparently high percentage who preferred Cambridge accounts for only 40 of the 119 "mobile" staff (out of the present total staff of 190 or so): replies from "mobile" staff who said they would resign rather than move anywhere and from "nonmobile" staff who face redundancy as a result of any move, were excluded. Staff who said they would follow the observatory wherever it went were added to the Cambridge-first-choice group. Fifty-five of the 119 did not reply at all to the questionnaire (many because they were fearful that the results would be misused). What price statistics?

Our strong desire to remain in Sussex is not blindly reactionary. If we could be convinced that there were clear and quantifiable benefits to be gained from moving to a different environment, we would welcome the proposal and consider the arguments on their merits: instead we are offered grounds which the council's officers themselves describe as a "matter of judgement" and "intangible" which to us as scientists is just not good enough. RGO staff wish to participate fully in the bright future for ground-based astronomy which the present facilities offer. A futile move would place this future in jeopardy and we urge our many supporters in the astronomical community to convey their views to SERC before it is too late.

JANET DUDLEY

(Chairman, RGO Staff Trades Union Side)

Royal Greenwich Observatory,

Herstmonceux,

Hailsham, Sussex BN27 1RP, UK

\section{Ageism}

SIR-Jürgen Neffe (Nature 320, 295; 1986) writes: "Although now 74 , von Weizsäcker's opinion is still influential in West Germany." The probably unintentional pejorative use of "Although now $74 . .$. " implies that the influence of an opinion should diminish with advanced age of the opiner.

This is an outdated, incorrect ageist myth. It is out of place in any publication intended to be a modern journal of science. I believe that an apology is due to Professor von Weizsäcker.

$$
\text { Arthur Cherkin }
$$

Geriatric Research, Education, and Clinical Center,

VA Medical Center,

Sepulveda, California 91343, USA

- The form of words correctly complained of was not that used by Jürgen Neffe but was introduced in the editing. - Editor, Nature. 